\section{Thinking about the ways of science}

\section{John Ziman}

Popper Selections.* Edited by David Miller. Princeton University Press: 1985. Pp.479. Hbk \$32.50; pbk\$9.95.

ANY natural scientist interested in the philosophy of science will be acquainted with the work of Karl Popper. His identification of "falsifiability" as the hallmark of a scientific theory is now so widely accepted that scientists even use it as a weapon in purely scientific controversies: "I know my theory is conjectural, but at least it could be refuted by the following experiment, whereas yours is so broad and vague that it could not be disproved" etc., etc.

Many scientists attracted to Popper's ideas will have read their way with profit and pleasure through his half-dozen or so major books, and come to appreciate the breadth and depth of his thought on the meaning and social significance of the scientific approach to the world - otherwise one would have had to be content with a version of these ideas at second hand, in one of the books that have been written about them by other philosophers. But Popper is not one of those gurus whose jewels can only be appreciated by cleaning away a mass of obscuring verbiage. Not all his writing is perfectly clear and transparent at the first reading - he is dealing, after all, with very difficult questions but there are many passages that sum up his arguments with extreme clarity and simplicity. David Miller's selection of some of these passages is thus an invaluable introduction to the work of one of the leading thinkers of our times.

It is not difficult to understand why working scientists are drawn to Popper's philosophy. His characterization of the work of research as the evolution of a body of knowledge through a process of trial and error resonates with their own experience, both as would-be discoverers and as critics of discovery claims. This overall account of the scientific process has, of course, been attacked in detail by numerous other philosophers, but it still stands firm. Indeed, the most striking feature of Popper's thinking and writing is that it is so robust. He fastens on a few very solid principles, and stands firmly on them throughout - the corrigibility of all scientific knowledge, the logical force of a disconfirmed prediction, the vapidity of philosophical idealism and, in the social sciences, the absurdity of the assumption that people always behave rationally. Knock-me-down arguments are not welcomed in professional academic life, which thrives on subtlety and equivoca-

*In Britain published by Fontana as $A$ Pocket Popper, pbk $£ 4.95$. tion, but I really wonder how the modern exponents of the sociology of knowledge would answer Popper's devastation of their position, originally published 40 years ago and still entirely valid.

Of course there are situations where reliance on a few apparently sound general principles can be misleading. Popper was once led into asserting that the principle of biological evolution was not a "scientific" hypothesis because it seemed essentially tautological: biologists will be pleased to read here a passage written in 1977 where he gracefully acknowledges his error on this point. I suspect that his remarks on "The Mind-Body Problem" and "The Self" will not stand for long, as natural,

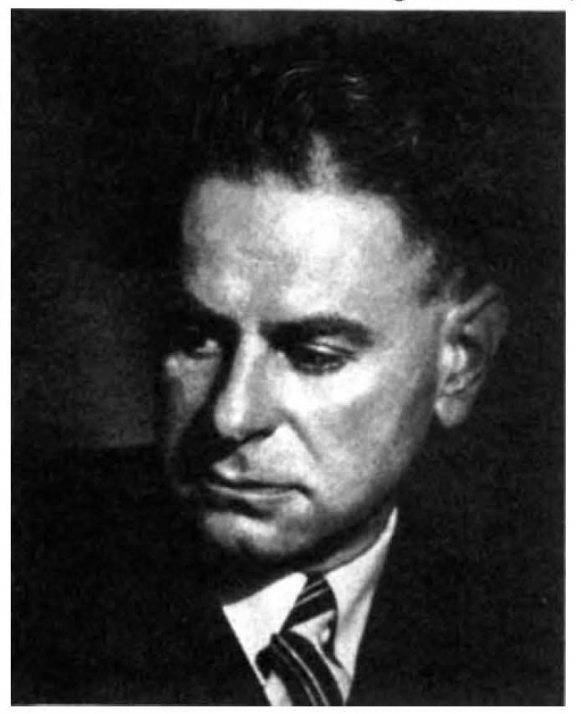

Man of principles - Karl Popper, a portrait from around 1950.

and social and behavioural scientists collaborate more closely in their accounts of consciousness and cognition. It is also surprising that the very clear conception of the "public" character of the scientific process, through the intersubjectivity of observation and the mutuality of creative criticism, which he gave in a page or two in 1945, scarcely figures in his later work. Again, his notion of "world 3" - that is, the domain of "the objective contents of thought", such as scientific theories and works of art - could have been made much more convincing and fruitful if it had been firmly related to the function of symbolic communication in human societies.

But in the end one comes back to Popper for his incisive commentary on the strategies of scientific and political action. He does not provide us with rules on which to act - indeed, his first rule would be that there are no such rules — but his critique of scientism and historicism is founded upon precepts which every scientist, every citizen, would ignore at their peril.

John Ziman is Visiting Professor in the Department of Social and Economic Studies, Imperial College, University of London, 53 Prince's Gate, Exhibition Road, London SW7 2PG, UK.

\section{Speechless in Java}

\section{John C. Marshall}

Ancestral Voices: Language and the Evolution of Human Consciousness. By Curtis G. Smith. Prentice-Hall: 1985. Pp.178. Hbk \$14.95, £17.50; pbk \$8.95, $£ 9.60$.

THE "ancestral voices" that Kubla Khan heard in Xanadu were "prophesying war"; the voices that appear in Curtis Smith's title are those of our purported evolutionary precursors who first developed the capacity for symbolic communication. But the parallels are somewhat too close for comfort. The archaeological record, Smith conjectures, suggests that linguistically-skilled Cro-Magnon "with his superior culture and technology" exterminated speechless Neanderthal man, "his closest rival for the riches of Europe".

Like so many eminent scholars before him, Curtis Smith, a professor of biological sciences at Mount Holyoke College, Massachusetts, has failed to resist the temptation to speculate on the evolution of language and consciousness. Professor Smith's mixture is fairly conventional: fossil remains, flint tools and progressive enlargement of the cerebrum, combined with attempts to teach chimpanzees American Sign Language and to communicate with hypothetical intelligences on other planets. The problem, however, is that whilst we have undoubtedly learnt much about the structure of the brain and much about the structure of human language we still have few (or no) coherent ideas about how to relate the two. That localized damage to different parts of the brain can result in differential loss of aspects of linguistic capacity and skill places constraints upon speculation but leaves the central issue untouched. Professor Smith has no more insight into that issue - how the brains of human beings differ from those of other higher primates such that only human brains can support a syntactically-structured language - than do the rest of us.

This leaves Smith to make some nonetoo-accurate general remarks about the functional organization of the brain. Thus he asserts that the brain resembles "an enormous hologram" in that "all of the neural symbols used for language, visual memories, music, feelings, are stored 'everywhere'". It may turn out that this claim is true, but it is grossly misleading to present the holographic hypothesis as already established fact; and it is even worse to do so without giving any indication of how such distributed informationstorage could be compatible with the specificity of deficit that is so often observed after focal damage. Smith's convictions are rarely backed by evidence. He simply states, for example, that "amnesias are defects in the retrieval system, not actual 